\title{
Engineering leadership: Grounding leadership theory in engineers' professional identities
}

\author{
Cindy Rottmann, Robin Sacks \& Doug Reeve
}

Version Post-print/ accepted manuscript

Citation Rottmann, C., Sacks, R., \& Reeve, D. (2015). Engineering leadership:

(published version) Grounding leadership theory in engineers' professional identities. Leadership, 11(3), 351-373.

Copyright / License The Author(s) 2014

Publisher's Statement Rottmann, C., Sacks, R., \& Reeve, D. Engineering leadership: Grounding leadership theory in engineers' professional identities. Leadership, 11 (3) pp. 351-373. Copyright (C) [2015] (The Author(s)). Reprinted by permission of SAGE Publications. DOI: $10.1177 / 1742715014543581$

How to cite TSpace items

Always cite the published version, so the author(s) will receive recognition through services that track citation counts, e.g. Scopus. If you need to cite the page number of the author manuscript from TSpace because you cannot access the published version, then cite the TSpace version in addition to the published version using the permanent URI (handle) found on the record page.

This article was made openly accessible by $U$ of $T$ Faculty.

Please tell us how this access benefits you. Your story matters. 


\title{
Engineering Leadership: Grounding leadership theory in engineers' professional identities
}

\author{
This is a version 2 copy of the article. It does not include all final edits. For the final \\ version of the article along with pagination and complete formatting, please see \\ http://dx.doi.org/10.1177\%2F1742715014543581
}

Rottmann, Cindy, Sacks, Robin, \& Reeve, Douglas W. (2015). Engineering leadership: Grounding leadership theory in engineers' professional identities. Leadership, 11(3), 351-373. doi: 10.1177/1742715014543581

\begin{abstract}
In recent years the US-based National Academy of Engineering (NAE) and Engineers Canada (EC) have urged engineering educators to supplement technical coursework with multiple domains of professional skills development. One such domain is that of engineering leadership. While leadership education is beginning to be infused into some undergraduate engineering programs, it has not yet gained traction as a legitimate field of study. The legitimacy of the field depends on engineers recognizing themselves as members of a leadership profession. Our paper facilitates this process of recognition by grounding leadership theory in the professional experiences of engineers employed by four Canadian engineeringintensive firms. Our constant comparative analysis of qualitative data collected through nine focus groups and seven interviews suggests that engineers are largely resistant to dominant leadership paradigms drawn from other disciplines, but that they do, in fact lead in ways that blend key aspects of their identities with professionally recognized forms of influence. Our compound model of engineering leadership has practical and theoretical implications for engineers, leadership theorists and engineering educators.
\end{abstract}

Keywords: leadership, engineering, grounded theory, professional identity, resistance

\section{Introduction: Engineering leadership depends on engineers recognizing} themselves as leaders

Recent policy documents and program reviews across international jurisdictions have encouraged engineering educators to bridge the school to work transition by supplementing technical coursework with social, communication and leadership skills training (Graham, 2012a, 2012b; NAE, 2004; Rover, 2006; Wakeman, 1997). While the inclusion of leadership training in undergraduate and graduate engineering programs has received support from the US-based National Academy of Engineering (NAE) and Engineers Canada (EC) (EC, 2009, 2012a; NAE, 2004, 2005), engineering leadership will not take hold as a legitimate field of study or practice until it is accepted and implemented by a critical mass of practicing engineers. The acceptance and implementation of engineering leadership education depends on wide spread recognition of engineering as a leadership profession.

Currently, there are at least four barriers to this recognition. First, the typical career trajectory of most engineers takes them through five to ten years of technical work 
into project or process management roles (Reese, 2003, 2004). For individuals whose love of engineering comes from their technical problem solving, the sudden shift to resolving "people problems" can feel both uncomfortable and un-engineerlike (Reeve, Sacks, Rottmann, Daniels, \& Wray, 2013). Second, engineers who hold a traditional, hierarchical view of leadership may experience the phenomenon as inconsistent with the egalitarian, team-based norms of their discipline (Breaux, 2006; Graham, 2012a). Third, the somewhat amorphous term "leadership" does not always resonate with members of an occupational group whose reputations hinge on their technical precision (Gopakumar, Dysart-Gale, \& Akgunduz, 2013; McGrath, 2010). Finally, when faculties of engineering support leadership primarily through optional, extracurricular involvement (Alajek, Ham, Murdock, \& Verrett, 2013; McGrath, 2010), a critical mass of students may view it as peripheral to the core curriculum.

Fortunately, the story is not all doom and gloom. These four barriers are surmountable so long as three conditions are met: First, engineering students must be socialized to think of their discipline as legitimately having both technical and humanistic elements (CEAB, 2008; EC, 2009; NAE, 2004). Second, engineers must be exposed to leadership education that forces them to unpack simplistic, traditional or hierarchical notions of leadership (Baranowski, 2011; Foster \& Sheridan, 2013; Grasso \& Martinelli, 2007; Harris, 1989) and third, engineering leadership must be more clearly defined on the basis of engineers' professional experiences (Andrews \& Farris, 1967; Reeve, 2010; Reeve et al., 2013). The first of these conditions was set into motion a decade ago by the NAE through The Engineer of 2020: Visions of Engineering in the new Century (NAE, 2004). The second is beginning to take hold in faculties of engineering across international jurisdictions through seed grants, industry support and faculty initiatives (Hsiao, 2013; NAE, 2005, 2013; Pitts, Klosterman, \& McGonagle, 2013; Polito \& Martinich, 2008; Simpson, Evans, \& Reeve, 2012). The third of these conditions-generating a clear, empirically based conception of engineering leadership derived from the actual work experiences of engineers-has not yet been addressed. Our paper fills this gap. In particular, we answer the following research question: How do engineers conceptualize leadership on the basis of their professional experiences in engineering-intensive firms?

We begin by briefly reviewing the literature on engineering leadership and describing our grounded theory methodology. Next, we present our findings and illustrate them through a theoretical model connecting engineering identity, traditional notions of leadership, resistance, professionally recognized modes of influence and three compound engineering leadership orientations. Finally, we compare these findings to long-standing leadership theories and identify implications of our study for leadership researchers, engineering educators and senior engineers working in industry.

\section{Literature review}

There is a small but growing body of literature in the emerging field of engineering leadership, much of it located within the larger field of engineering education, and 
most of it published within the last decade. The earliest texts constitute calls for reform in engineering education. These were followed closely by engineering leadership program descriptions. Outside the field of engineering education, mainstream leadership theories have been applied to engineers' work. The three most common sources are engineering education conference proceedings, Leadership and Management in Engineering and the Journal of Engineering Education. Before presenting our findings, we briefly review this body of literature.

Calls for reform have come from national engineering organizations (EC, 2009, 2012b; NAE, 2004, 2005, 2012, 2013) as well as from professional engineers themselves (Baranowski, 2011; Bonasso, 2001; Cassin, 2003; Flowers, 2002; Ivey, 2002; Kalonji, 2005; Katehi, 2005; King, 2012; Kirschenman, 2011; Mawson, 2001; Pierson, 2013; Reeve, 2010; Vest, 2005). These calls are based on two complementary, but distinct, rationales. The rationale first articulated by the NAE enlists a global competition argument-the United States will fall behind other nations if graduates of engineering programs are exclusively trained in technical problem solving. Stated differently, global mobility and competition resulting from increasingly transnational economies demand that North American engineers lead cross-cultural, inter-disciplinary teams and respond to a range of stakeholder concerns. They cannot do this without merging the humanistic and technical elements of their profession. A related rationale for merging technical and humanistic aspects of engineering is rooted in the idea of professional service (Bonasso, 2001; Cassin, 2003; Grasso \& Martinelli, 2007; Hill, Lorenz, Dent, \& Lutzkendorf, 2013; Mawson, 2001; Pierson, 2013; Vallero, 2008; Wakeman, 1997). This line of thinking suggests that it is the professional responsibility of engineers to take leadership roles in infrastructure development, public safety, environmental sustainability and community building. They must not only solve other people's problems accurately and efficiently, but must also use their knowledge, training and expertise to ethically frame these problems for themselves and for their profession.

The NAE's calls for reform have been taken up and implemented by many faculties of engineering (See for example, Athreya et al., 2010; Bayless, 2013; Cain \& Cocco, 2013; Ellis \& Petersen, 2011; Froyd, 2005; Ha, 2013; Hsiao, 2013; Kerns, Miller, \& Kerns, 2005; Kumar \& Hsiao, 2007; McCuen, 1999; NAE, 2005; Osagiede, Farmer Cox, \& Ahn, 2013; Pitts et al., 2013; Simpson et al., 2012; Strong \& Frank, 2013) resulting in an amazing range of delivery options and program elements. Engineering leadership education is currently offered through self-contained programs, stand-alone courses, co-curricular offerings, multi-year team projects, service learning opportunities, problem-based learning, coaching, mentorship, interdisciplinary team projects, professional learning communities, industry-sponsored "grand challenges" and institutional cooperation between two or more university faculties. The growing number of conference presentations and journal articles on engineering leadership education is impressive, but they are generally limited to authors' promotional descriptions of their own programs. The one exception to this trend is a large-scale review of 40 international engineering leadership programs (Graham, 2012a, 2012b; Graham, Crawley, \& Mendelsohn, 2009). Graham and her 
colleagues' central finding was that engineering leadership programs were prevalent but insufficiently systemic - piecemeal, isolated and lacking in institutional support.

Studies of engineering leadership in the workplace are less prevalent, but more often empirically based than engineering education program descriptions. Some researchers focus on the distinct leadership needs of employers in specific industries such as high-risk workplaces (Martines-Corcoles, Gracia, Tomas, Peiro, \& Schobel, 2013; Slates, 2008; Snowball \& Travers, 2012), public works (Singh \& Jampel, 2011) and the military (Flowers, 2002; Locurcio \& Mitvalsky, 2002), while others apply traditional leadership theory to a subset of the engineering workforce. Research studies and professional development programs framed using transformational leadership (Breaux, 2006), servant leadership (Croft, Winkelman, Boisvert, \& Patten, 2013), self leadership (Colcleugh \& Reeve, 2013; Porter, 1993) and authority leadership (Ning, Zhou, Lu, \& Wen, 2012; Zhou \& Liu, 2011) aid interdisciplinary comparisons of leaders, but they disadvantage engineers by measuring them against standards set by researchers familiar with other disciplinary norms.

The three authors who have come closest to conceptualizing "engineering leadership" in an analytically clear manner are Farr, Mallette and Robledo (Farr \& Brazil, 2009; Farr, Walesh, \& Forsythe, 1997; Mallette, 2005; Robledo, Peterson, \& Mumford, 2012). Farr and his colleagues identify nine key leadership qualities relevant to engineers-big thinker, ethical and courageous, masters change, risk taker, mission that matters, decision-maker, uses power wisely, team builder and good communicator; Mallette (2005) draws on 30 years of experience in the aerospace industry to construct a leadership style best suited to the management of engineers; and Robledo , Peterson \& Mumford (2012) propose a three-vector model of leadership to accommodate the creative work of scientists and engineers. Farr, Mallette and Robledo have laid the necessary groundwork for a discipline-specific theory of engineering leadership, but they tend to focus on how best to lead engineers, not how engineers lead.

Our brief review of the literature suggests that there is a growing body of knowledge on engineering leadership, but that this knowledge is limited by an editorial rather than empirical approach to program evaluation, a descriptive rather than analytic treatment of data and excessive attention to the management of engineers. A significant conceptual gap remains. In part, this gap arises from our cultural familiarity with the word "leadership." We all know what we mean when we use the term and most of us can identify a living, breathing specimen. Unfortunately, the cross-cultural prevalence of the word causes us to skip over the important work of defining it. Engineering leadership has been advocated for, implemented in universities and evaluated against traditional leadership standards, but it has yet to be defined. Our paper returns to the conceptual starting point-that is, we examine what constitutes engineering leadership from the perspectives of engineers working in four Canadian engineering-intensive organizations. 


\section{Methodology: Grounded Theory}

This paper addresses the first of three research questions driving a larger mixedmethod study of engineering leadership-“How do engineers conceptualize leadership?" The paucity of research on engineering leadership shaped our decision to employ a grounded theory (Glaser \& Strauss, 1967) approach to data collection and analysis for our initial qualitative phase. First proposed in 1967 by Glaser and Strauss, the intent of grounded theory is to generate an integrated set of concepts that describes and explains complex social phenomena in context. In the 46 years since it was first introduced, there have been many epistemological and procedural splits between Glaser, Strauss and their respective followers. Fortunately, a few core ideas remain intact-data collection and data analysis occur simultaneously (Glaser \& Strauss, 1967); data analysis occurs through an iterative process referred to as "constant comparison" (Corbin \& Strauss, 1990; Glaser, 1965; Glaser \& Strauss, 1967); coding is the fundamental analytic process (Corbin \& Strauss, 1990; Glaser \& Strauss, 1967); concepts are the basic units of analysis (Corbin \& Strauss, 1990; Glaser \& Strauss, 1967); sampling proceeds on theoretical grounds and continues until all concepts reach the point of theoretical saturation (Corbin \& Strauss, 1990; Glaser, 1965; Glaser \& Strauss, 1967) and the final theory is judged by fit, relevance, workability and modifiability (Glaser \& Strauss, 1967) rather than truth value, validity or reliability.

Our sampling and analytical decisions were driven by each of these core criteria. Our initial site selection strategy combined convenience, purposive and (Miles \& Huberman, 1994) theoretical (Glaser, 1978, 2013; Glaser \& Strauss, 1967) sampling. We began by generating a list of engineering intensive firms in the greater Toronto (Ontario, Canada) area and assigning a point value for each of our purposive and convenience criteria. Purposive criteria included engineering concentration, commitment to leadership development and a cross section of engineering disciplines. Our convenience criteria included geographical proximity, institutional ties to the University of Toronto and member of our organizational network. The senior member of our team contacted the Chief Executive Officer of high scoring organizations and pitched our research proposal. Four engineering-intensive organizations in four distinct industry sectors-chemical, civil consulting, software, mining \& metal processing - met our criteria and consented to participate in the study. All four companies have international offices; however, we exclusively sampled staff working in two Canadian provinces-Ontario and Quebec. The Canadian offices of the two smaller companies employed approximately 400 people, while those of the two larger companies employed approximately 4000 people. Theoretical sampling continued throughout the analytic process as we sought out new groups of engineers to fill conceptual gaps.

While our decision to focus on Canadian organizations was primarily a product of convenience, we believe there is value in examining engineering leadership in this national context. Canada is a relatively decentralized, middle-power geo-political entity that has become increasingly subject to and increasingly able to take 
advantage of global policies, legislations and reform movements. As signatories of the Washington Accord (1989) —an international engineering education accreditation agreement-Canadian engineers have entered an era of global accreditation standards (Gopakumar et al., 2013; Sweeney, 2005). A strong indication of this influence is the congruence between the Canadian Engineering Accreditation Board graduate attributes (CEAB, 2008, 2012; EC, 2012b) and those generated by the American Accreditation Board for Engineering and Technology (ABET, 2011). Internationally harmonized education standards aside, engineers in Canada fall under provincial jurisdiction and thus continue to exert professional autonomy at a more local level (PEO, 2013). Our research on engineering leadership in a Canadian context allows us to examine how a particular global reform idea targeting higher education-engineering leadership—has landed in a provincial context where leadership has not yet been fully accepted as a key component of engineers' professional identities.

To date, we have conducted 9 focus groups and 7 interviews with junior engineers, senior engineers and Human Resource professionals working in four engineeringintensive firms. Focus groups and interviews were audiotaped with permission and transcribed verbatim yielding 721 pages of qualitative data. Our decision to conduct focus groups emerged from our interest in discovering engineers' leadership discourses. Preliminary analysis of the first three focus groups taught us that many engineers resisted the idea of leadership because they found it to be inconsistent with their professional identities as engineers. We attempted to sidestep their resistance in future focus groups by asking them to play a skill/attribute sort card game with the idea of professional success in mind. Our analysis of this activity and the follow-up line of questioning about influential colleagues allowed us to conceptualize three distinct engineering leadership orientations. We presented our preliminary findings to representatives from each of the four organizations at a community of practice conference and incorporated their feedback into future iterations of our emerging engineering leadership theory. With this preliminary theory in mind, we began to organizationally contextualize our findings through key informant interviews with Human Resource Professionals at each of the four organizations. We also conducted an additional focus group with engineering entrepreneurs to test our initial finding of resistance.

At each stage of data collection, we analyzed transcripts using a combination of open, axial, selective and theoretical coding (Corbin \& Strauss, 1990; Glaser, 1965, 2013; Hernandez, 2009; LaRossa, 2005). Open coding involved labeling every line of every transcript with one or more conceptually meaningful "codes," grouping similar codes into categories, iteratively comparing similar categories with additional data and marking distinctions with sub-categories. Our use of the "constant comparative" method (Glaser, 1965) enabled us to sort data on a conceptual basis and iteratively revise code names so they reflected participants' experiences. Eventually, our conceptual revision process decelerated with each new data source. This early sign of data saturation caused us to shift our attention to axial coding. We followed Corbin and Strauss' (1990) protocol for axial coding by 
hypothesizing the conditions, contexts, actions and consequences shaping each category and sub-category. As our process of revising hypotheses to accommodate new data decelerated, we turned our attention to selective and theoretical coding. Selective coding involved limiting our analysis to a key analytic code and its related sub-categories while theoretical coding involved threading together actors' perspectives about this key concept to generate an experientially grounded theoretical model.

\section{Finding I: Leadership is not us!}

A useful point of departure for grounded theorists is to ask what problem or problems actors are grappling with in relation to researchers' phenomena of interest (Glaser, 2004; LaRossa, 2005). Our phenomenon of interest is engineering leadership. Unfortunately, as we began to conduct focus groups and analyze transcripts, it became clear to us that the majority of engineers in our sample found leadership to be imprecise, impractical, elitist and just "not us." The quotation below illustrates several of these dimensions:

The connotation that this word [leadership] carries is sort of antithetical to the engineering mind-set from my point of view. For example, the notion of standing on top of a hill, waving the flag, sitting on your horse with the peasants behind you carrying their [pitch] forks is the exact opposite of anything I personally or anyone I know wants to do.

Implicit in participants' multi-dimensional resistance was an element of cognitive dissonance between their professional identities as engineers and their views of leadership as antithetical to these strongly held identities. Please see table one for a list of engineers' key identity features and their traditional notions of leadership.

Table 1: Mismatch between Engineers' identities \& traditional notions of leadership

\begin{tabular}{|lll|}
\hline Key features/ & Engineers professional identities & Traditional notions of leadership \\
Dimensions & Service professional & Charismatic visionary \\
& Team work & Positional influence at top of hierarchy \\
& Technical problem solver & "Great man"-an agentic individual \\
& Task-oriented doer & Solves people problems \\
& Process optimizers & Delegator \\
\hline
\end{tabular}

When we analyzed the tensions between engineers' identity features and their conceptions of leadership, we found six professionally specific dimensions of resistance. First, the strategic plans of charismatic visionaries seemed imprecise and impractical to applied scientists. Second, hierarchical notions of leadership felt uncomfortable and elitist to engineers who defined themselves as service professionals. Third, the individualism implicit in "great man" theories of leadership contrasted with the collaborative nature of engineers' day to day work. Fourth, engineers who depend on rationality and objective data to solve technical problems felt unprepared to resolve the highly subjective and often emotional people problems faced by most managers. Fifth, engineers who prided themselves on being task- 
oriented "doers" tended to have limited respect for managers who delegated tasks to others. Finally, engineers dedicated to optimizing a particular product or process struggled to keep up with their iterative work when internal change agents kept restructuring the order of things. These six dimensions of resistance suggest that engineers' expertise and core identity features-applied scientist, service professional, team player, technical problem solver, task oriented doer, and process optimizer-find little space for expression in traditional performances of leadership.

Our finding of widespread resistance posed a problem. How could we study the phenomenon of "engineering leadership" from the perspective of engineers when so many engineers experienced "engineering" and "leadership" as incompatible terms? We addressed this challenge by noting that participant's "theories in use" differed from their "espoused theories" (Argyris \& Schon, 1974) of engineering leadership. That is, while they espoused the belief that engineering was inconsistent with the idea of leadership, they easily recalled examples of influential engineering colleagues leading in their workplaces. Stated more succinctly, a critical mass of engineers dismissed the idea of "engineering leadership" in the same breath as they told us stories about engineer leaders. Their stories suggest that engineering practice involves professionally legitimate forms of influence whether or not engineers self-identify as "leaders." Our open coding process helped us identify three ways in which engineers lead.

\section{Finding 2: Three orientations to engineering leadership}

Participants' experientially informed stories revealed the workplace reality that while engineers may resist the idea of leadership, they do, in fact, lead. Engineers in all four of the organizations we studied led in at least three ways. They shared their well-developed technical problem solving skills with others through informal mentorship-technical mastery; they built effective and efficient teams across organizational units by learning about and leveraging their colleagues' strengthscollaborative optimization and they used entrepreneurial thinking to bring technically sound ideas to market-organizational innovation. We refer to these three distinct conceptions of engineering leadership as orientations to highlight their developmental rather than deterministic nature. Please see table two for a summary of these findings.

Table 2: Three Orientations to Engineering Leadership

\begin{tabular}{|llll|}
\hline & Technical Mastery & $\begin{array}{l}\text { Collaborative } \\
\text { Optimization }\end{array}$ & $\begin{array}{l}\text { Organizational } \\
\text { Innovation }\end{array}$ \\
\hline $\begin{array}{l}\text { Brief } \\
\text { description }\end{array}$ & $\begin{array}{l}\text { Technical expertise } \\
\text { passed on through } \\
\text { informal advice and } \\
\text { mentorship. }\end{array}$ & $\begin{array}{l}\text { Skilled facilitation of } \\
\text { group process with an } \\
\text { eye to quality, efficiency } \\
\text { and engagement. }\end{array}$ & $\begin{array}{l}\text { Visionary realization of } \\
\text { practical, entrepreneurial } \\
\text { and intrepreneurial ideas. }\end{array}$ \\
\hline Who? & $\begin{array}{l}\text { The engineer you most } \\
\text { often go to with your } \\
\text { technical questions }\end{array}$ & $\begin{array}{l}\text { The engineer who builds } \\
\text { high performing teams by } \\
\text { bringing out the best in } \\
\text { everyone }\end{array}$ & $\begin{array}{l}\text { The engineer whose } \\
\text { creative ideas drive the } \\
\end{array}$ \\
& & & company \\
\end{tabular}




\begin{tabular}{|c|c|c|c|}
\hline $\begin{array}{l}\text { Key features- } \\
\text { Technical }\end{array}$ & $\begin{array}{l}\text { Technical expertise } \\
\text { Subject matter specialist; } \\
\text { skilled application of } \\
\text { science; high level pattern } \\
\text { recognition; creative and } \\
\text { detailed analysis of } \\
\text { technical problems }\end{array}$ & $\begin{array}{l}\text { Process optimization } \\
\text { Interdisciplinary } \\
\text { technical generalist; } \\
\text { skilled at matching } \\
\text { project objectives, team } \\
\text { member skills and } \\
\text { resources; balances } \\
\text { quality and efficiency }\end{array}$ & $\begin{array}{l}\text { Innovation } \\
\text { Industry knowledge; } \\
\text { critical, "outside the box" } \\
\text { thinker; takes calculated } \\
\text { risks and learns from } \\
\text { mistakes; develops } \\
\text { patents and publications; } \\
\text { problem posing }\end{array}$ \\
\hline $\begin{array}{l}\text { Key features- } \\
\text { Influence }\end{array}$ & $\begin{array}{l}\text { Mentorship } \\
\text { Coaches junior and senior } \\
\text { engineers; listens to and } \\
\text { understands others' } \\
\text { questions; clearly } \\
\text { explains complex } \\
\text { problems to a range of } \\
\text { audiences; "go-to" } \\
\text { technical resource for } \\
\text { organization }\end{array}$ & $\begin{array}{l}\text { Team Catalyst } \\
\text { Facilitates } \\
\text { interdependence; fosters } \\
\text { growth through critical } \\
\text { feedback; helps team } \\
\text { adapt to change and } \\
\text { conflict; inspires and } \\
\text { motivates team members; } \\
\text { leverages colleagues' } \\
\text { strengths }\end{array}$ & $\begin{array}{l}\text { Realization } \\
\text { Anticipates trend and } \\
\text { plans strategically; } \\
\text { change agent } \\
\text { (intrepreneur); } \\
\text { establishes start ups } \\
\text { (entrepreneur); } \\
\text { implements ideas to } \\
\text { benefit clients and } \\
\text { respond to market trends }\end{array}$ \\
\hline $\begin{array}{l}\text { Primary level } \\
\text { of influence }\end{array}$ & Dyad & Team/Department & Organization \\
\hline $\begin{array}{l}\text { Job satisfaction } \\
\text { derived from }\end{array}$ & Life long honing of craft & $\begin{array}{l}\text { Extensive professional } \\
\text { networks }\end{array}$ & Realized visions \\
\hline $\begin{array}{l}\text { Organizational } \\
\text { benefits }\end{array}$ & $\begin{array}{l}\text { Builds client trust and } \\
\text { market-share through } \\
\text { strong technical } \\
\text { reputation; builds } \\
\text { organizational capacity } \\
\text { for problem solving; } \\
\text { fosters organization-wide } \\
\text { learning through informal } \\
\text { apprenticeship system }\end{array}$ & $\begin{array}{l}\text { Reduced time spent } \\
\text { dealing with micro- } \\
\text { political tensions; } \\
\text { satisfied employees } \\
\text { working to their } \\
\text { potential; improved } \\
\text { relationships between } \\
\text { geographically disparate } \\
\text { offices }\end{array}$ & $\begin{array}{l}\text { Diffusion of a creative, } \\
\text { start-up ethos across the } \\
\text { organization; } \\
\text { organization becomes } \\
\text { increasingly responsive } \\
\text { to technical and economic } \\
\text { trends; job creation; } \\
\text { institutionalization of } \\
\text { new technologies }\end{array}$ \\
\hline
\end{tabular}

\section{Technical Mastery}

Participants consistently spoke with great admiration about the engineers in their workplaces who were skilled at solving technically challenging problems, especially when these colleagues were known to support others. We refer to this engineering leadership orientation as technical mastery. Dimensions of technical mastery include: subject-matter expertise; integrated, holistic application of mathematical and scientific theory; creative, dynamic problem solving; second nature pattern recognition/thinking in patterns; confidence in their own technical competence; peer-recognized expertise and the ability to comprehend colleagues' questions, clarify their confusion and support their growth through formal and informal mentorship responsibilities. Participants from all four organizations described the implicit collegial nomination process used to identify individuals with this leadership orientation:

Leadership is often implicit, and you will be implicitly chosen by your peers...In a team, you are going to have somebody who just kind of emerges...the real leader where the rubber meets the road is your tech lead. 
We conceptualized this orientation as technical mastery because of the qualitative distinction between integrated problem solving expertise and the otherwise successful application of knowledge, procedures and tools demonstrated by many experienced engineers. One participant made a useful chess analogy:

I will try to use an analogy...playing chess. Most people learn to play chess in more or less the same way. You learn about the way that the pieces move and then you learn about the point values of the pieces...A master doesn't play chess that way. A master sees the board as a collection of imbalances between two very evenly matched sides...these are features that the amateur chess player can't perceive at all. They get that only through years and years of play. Trying to bring this back to the real topic of discussion here, typically undergraduates...[are] still thinking in chess tactics format of "hey, this idea would be good because of these specific tactical considerations," but they can't see the broader pattern of what is going on in the world to say, "my vision is the right vision, not just because I think it's a good idea, but because it matches the state of play of the board."

Engineers identified by their colleagues as "go-to" technical specialists in their organizations not only knew how to use engineering tools in a reliable manner; they were also able to creatively synthesize all relevant contextual factors before solving complex problems. As an engineering leadership orientation, Technical mastery integrates elements of mentorship, coaching and communication with high level computational, pattern recognition and creative problem solving skills. Engineers, who are strongly oriented to the technical elements of their jobs and have been recognized by others as competent in this realm, lead by inspiring colleagues to set high standards for technical problem solving. Beyond this inspirational role, they lead through formal and informal mentorship responsibilities. Informally, they function as translators of complex concepts and coaches for junior engineers who need help trouble-shooting. Formally, they are often promoted to "Tech Lead" positions, called upon to coach junior engineers through organizationally implemented mentorship programs and invited to explain complex technical concepts to clients with non-engineering backgrounds. While technical mastery primarily takes place at the individual and dyadic level, a multiplication of dyadic interactions between highly skilled problem solvers and novice engineers can accelerate organizational learning in a practical, project-specific way that mirrors an apprenticeship model, whereby the apprentice has multiple formal and informal guides. Individuals who embody this orientation gain job satisfaction from the lifelong honing of their craft while their organizations benefit from enhanced organizational learning systems and an exemplary technical reputation among industry leaders.

\section{Collaborative Optimization}

Collaborative optimization was the most regularly characterized leadership orientation across the four organizations we studied. Individuals who embodied 
this orientation tended to build and catalyze high performing teams by bringing out the best in everyone. The prevalence of this orientation reflects the centrality of teamwork in engineering-intensive organizations.

The majority of engineers in an engineering company are working in teams. No one person can understand everything about a system, you need the people who are specialists in pipeline design, electrical engineering - and even within electrical engineering you have so many different facets of it, so teamwork is something that is crucial to our engineering education and that helps develop great leaders.

The need for effective team leadership arises because no individual specialist, regardless of his or her competence, can independently deliver a large project. Rather, inter-disciplinary teams assembled and facilitated by mid-career and senior engineers function as the primary vehicles of product and process delivery in engineering-intensive firms. The dimensions of collaborative optimization include: facilitating interdependence; optimizing team process; motivating and enabling others; balancing quality, efficiency and engagement; building bridges across organizational units; leveraging team members' strengths; skilfully assembling inter-disciplinary teams; exhibiting organizational savvy; managing conflict through collegial communication; collective problem solving; shared responsibility; selforganizing systems and the establishment of feedback networks. The two quotations below illustrate these dimensions - the first foregrounding an individual catalyst within a team context, and the second describing an organizationally infused mentality of shared responsibility:

Leadership to me today, at least inside of [XX], is more about being an efficient component of a self-organizing system...If you throw me into one of these systems, I am not going to become the leader of the pack, but I am going to make it work better...what happens to me personally is that I get thrown into more and more exciting packs. It's like [my colleagues] know that whenever [I am] in one of these groups, [I] will make it work so much better.

When there is a problem and something goes wrong, everyone steps up and says, "how can we help to fix it?" That happens all of the time here. It's never a case of, "that's not my problem."

Engineers who are known for assembling high-performance inter-disciplinary teams by leveraging the strengths of their colleagues most closely resemble the ideal of engineering leadership described by the NAE (2004). That is, they skilfully strike a balance between the humanistic and technical aspects of the profession. These engineers may occupy formal positions as team leaders or they may simply be known as catalysts for effective self-organizing teams, but in all cases, they positively impact the organizational culture. The second quotation suggests that the organizational culture itself may be a powerful source of group influence. In this 
way, the collaborative optimization orientation to engineering leadership is not only a property of individual catalysts, but also a collective property of groups and organizations (Ogawa \& Bossert, 1995). Engineers who embody a collaborative optimization leadership orientation derive job satisfaction from extensive professional networks and high quality project delivery, while their organizations benefit from productive, collegial relationships between employees.

\section{Organizational Innovation}

Finally, engineers in all four organizations spoke about colleagues and senior administrators who used entrepreneurial thinking to bring technically and scientifically sound ideas to practice and to market. We refer to this engineering leadership orientation as organizational innovation. Engineers with an organizational innovation orientation to leadership are similar to entrepreneurs and intrepreneurs ${ }^{1}$ in other disciplines, but they are more likely to anchor their ideas in technology (software platforms, chemical processes, structural consulting practices, sustainable mining processes and other concrete, material systems). Participants with relatively long institutional memories at all four organizations spoke with great respect about chief executive officers, directors and other senior engineering leaders who had planted a technical seed and nurtured the resulting product, process or patent from the ground up. In many cases, as illustrated by the quotation below, they operationalized ideas through start-ups and grew start-ups into larger organizations:

Honestly, in the case of a small company that grew like this, I feel it is a function of the initial ingredients. It is really the culture established by the first couple of people here.

While our recent survey results suggest that organizational innovation is most prevalent at the latter stages of one's career, this leadership orientation is not the exclusive property of engineers at the top of the organizational hierarchy. Junior and intermediate engineers in all four organizations, as well as engineers of all ages and stages in our entrepreneur focus group found ways to influence organizational practices by repeatedly challenging the standard view on a range of issues. The dimensions of organizational innovation emerging from our data analysis process include: operationalizing innovative ideas; system planning; establishing organizational culture by example; big picture thinking; problem posing; thinking outside the box; realizing a vision; institutionalizing best practices; taking risks; learning from failure; founding start-ups; persuading others to follow; catalyzing change; market savvy and identifying opportunities. The dimensions of problem posing, thinking outside the box and identifying opportunities are illustrated by the quotation below:

\footnotetext{
${ }^{1}$ Many engineers work within existing organizations to innovate or introduce change from within-a practice referred to in some engineering and business journals as "intrepreneurship" (see for example, Hanifin, Lee, Weaver, Bloemer, \& Fry, 2013).
} 
Colleagues who I perceive as effective often have a broader picture of what is going on, so they know they are solving the right problems as opposed to just doing the best job solving this problem. You might call that sort of a renaissance engineer.

Engineers with an organizational innovation orientation to leadership derived career satisfaction from realizing their visions on a larger scale than would have been possible through individual problem solving. Beyond job satisfaction, they benefited their organizations and society by institutionalizing and producing new technologies and processes, establishing patents and creating jobs for technical professionals.

\section{Finding 3: Reconsidering the centrality of resistance}

Many of our focus group participants who resisted the notion of engineering leadership rationalized their resistance by suggesting that it was not an engineer's job to identify problems. Rather, it was his or her responsibility to solve problems identified by others. In contrast to the large majority of engineers who expressed this view, those who self-identified or were identified by others as innovators at the organizational level expanded the permissible range of engineering influence beyond technical problem solving. The engineers who inhabited this expanded role were more likely than their colleagues to accept, and in some cases even promote, the idea of engineering as a leadership profession:

The risk of not talking about leadership...might have...consequences. I would really want to see more engineers running our city or running our financial institutions or parts of our government, just because of the technical ability and all of the other problem solving, critical thinking, etc...I don't know how you do it without using either the word leadership or concepts like that.

The focus group participants-mostly entrepreneurs-whose perspectives aligned with the sentiments expressed in the above quotation were least likely to espouse traditional "great man" theories of leadership. Rather, they spoke of engineering leaders as coaches, public servants, inventors and organizational capacity builders. Their experiences, identities and perspectives forced us to revise our emergent theory of engineering leadership so that it no longer depended on resistance as a universal condition. We present this preliminary theory in the next section.

\section{Theorizing \& Modeling Engineering Leadership}

In contrast to experimental studies in which theories and hypotheses are empirically tested, grounded theories are empirically and iteratively generated. Our theory of engineering leadership grounded in the experiences and perspectives of engineers and human resource professionals employed by four engineeringintensive organizations is schematically represented by Figure 1. 
Figure 1

Engineering leadership: the emergence of a compound professional identity

Engineering identity

$+$

Conceptions of leadership

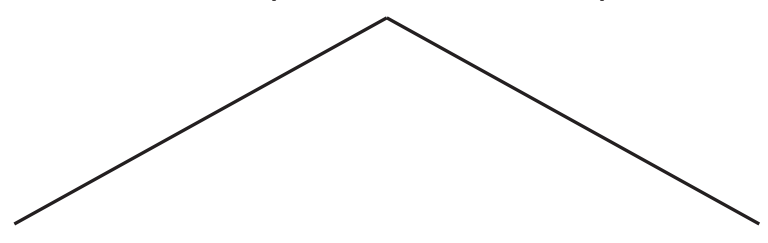

Traditional notions

of leadership

$\downarrow$

Professionally-recognized

forms of influence

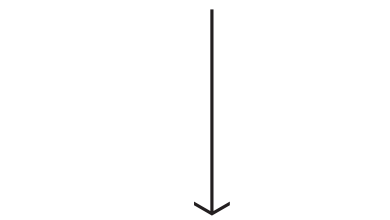

Resistance to leadership

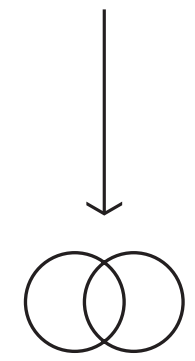

Compound professional identity:

engineering leader

Three orientations to engineering leadership

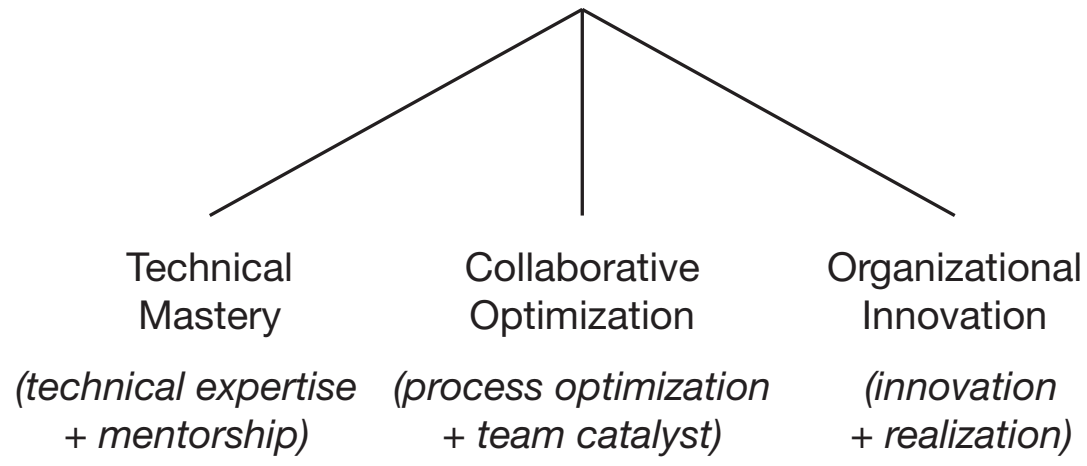

Our figure highlights the centrality of two variables-engineers' professional identities and their conceptions of leadership-to their acceptance or rejection of a leadership identity. When this identity is combined with traditional conceptions of leadership (left branch), engineers tend to resist identifying themselves or their colleagues as leaders. When this identity is combined with alternative, professionally meaningful conceptions of leadership (right branch), they tend to embrace, or at least accept, the idea of an "engineering leader." That is, without 
merging two elements-engineering identity and professionally relevant forms of influence-engineers are likely to resist leadership for themselves and for their colleagues. So long as these two key elements are merged, engineers are willing and able to accept leadership as a legitimate aspect of their work.

The compound identities depicted one layer down on the right branch merge aspects of engineers' professional identities-technical expertise, process optimization and innovation - with three professionally-relevant modes of influence-mentorship, team catalysis and realization. We used a Venn diagram to illustrate this compound identity with the left circle representing engineering identity, the right circle representing predominant modes of influence and the overlapping region reflecting our phenomenon of interest-engineering leadership. The final layer breaks this phenomenon of interest into three sub-categoriestechnical mastery, collaborative optimization and organizational innovation. The words in brackets below each orientation specify the two elements of each compound identity.

Our grounded theory of engineering leadership suggests that two conditions reduce the likelihood of resistance. First, when engineers can see beyond the "great man " conception of leadership, as is the case with many technical entrepreneurs, they are able to accept leadership roles without compromising or rejecting their professional identities. Second, when the word "leadership" is left out of the conversation, it is possible for engineers whose assumptions about leadership remain narrowly traditional to envision and accept the idea of professional engineering influence at the individual, team, organization and even societal level. These findings suggest two important implications for engineering leadership educators: first, we must help engineering students unpack their traditional notions of leadership and second, if we want our curriculum design efforts to be effective, they should be built on key features of engineers' professional identities and organizationally meaningful modes of influence.

\section{Discussion: Mapping findings onto Leadership Theory}

Conceptual elements within our model overlap in significant ways with ideas present in the leadership literature. For example, the idea of technical mastery blends Goleman's "pacesetting style" with his "coaching style" of leadership (Goleman, 2000) and is a close approximation to Mallette's "Theory Pi" (2005). The idea of collaborative optimization reflects an interesting blend of transformational (Bass, 1985; Burns, 1978; Weber, 1947), transactional (Bass, 1985; Burns, 1978; Weber, 1947) and distributed leadership (Gronn, 2002, 2008; Spillane, 2006), and the idea of organizational innovation reflects a highly practical version of "visionary leadership" (Nanus, 1992). Finally, our three orientations to leadership loosely correspond with Adizes' (1976) producer (technical mastery), integrator/administrator (collaborative optimization) and entrepreneur (organizational innovation) roles. We expand on these relationships in the paragraphs that follow. 
Goleman's (2000) pacesetting style of leadership involves setting and exemplifying high performance standards, while his coaching style focuses on the personal and professional development of employees. Engineers capable of merging these two styles are most likely to be oriented to leadership as technical mastery. They are also most likely to take on a "producer" (Adizes, 1976) role within their organization. Of our three leadership orientations, technical mastery is the only one to be characterized in the engineering leadership literature-through Mallette's (2005) Theory Pi. The added contribution of Technical Mastery over Theory Pi is that it encompasses the work of engineers as leaders, not just leaders of engineers. Unfortunately, while most engineers with this dyadic approach to leadership are valued as technical resources, they tend to be invisible as leaders. This is because they are rarely located near the top of their institutional hierarchies. They are responsive rather than commanding and pass on insights when employees run into technical challenges. In this way, they function as "servant leaders" (Greenleaf, 1977) with technical expertise.

In contrast to the somewhat invisible leadership orientation of technical mastery, the vast majority of focus group participants based their definitions of engineering leadership on the work of individuals in formal, highly visible positions of responsibility - team leaders, project leaders and process leaders. The most highly valued engineers in these middle management positions were known for their skilled facilitation of group process, their ability to build bridges between organizational units, and their capacity to leverage and acknowledge team members' strengths. We refer to this engineering leadership orientation as collaborative optimization. When mapped on to traditional leadership theory, collaborative optimization recalls the relational aspects of transformational leadership (Bass, 1985; Burns, 1978; Weber, 1947), the specialized training inherent in transactional leadership (Bass, 1985; Burns, 1978; Weber, 1947), the participative elements of distributed leadership (Gronn, 2002, 2008; Spillane, 2006) and Adizes (1976) organizational roles of "integrator" and "administrator." Like engineers known for their technical mastery, those recognized for their collaborative optimization were described as "doers" with sufficient knowledge and experience to understand the projects they were managing. Their integrative role occasionally involved delegation, but this delegation was always based on tight relationships between project objectives and team members' skills and stated interests.

Finally, our third orientation to engineering leadership-organizational innovation - maps onto Nanus' (1992) theory of visionary leadership and reflects Adizes' "entrepreneur" (Adizes, 1976) role. Nanus theorizes leadership as a futureoriented endeavour that not only requires an attractive or engaging vision, but also has to be sufficiently realistic to be practically achievable. Like transformational leadership, visionary leadership depends on persuasion, but it draws on an attractive, imagined future rather than an attractive, charismatic personality. Organizational innovation goes one step further than visionary or transformational leadership in that the vision must be operationalized. Berger and Luckmann's 
(1966) dual process of realization - the apprehension of an idea as real and the process of making it real-clarifies this distinction. Both visionary leadership and organizational innovation depend on the apprehension of a future-oriented vision as realistic (realization as recognition). However, only organizational innovation requires the vision to be transformed into a useable product, process or patent (realization as operationalization). The practical nature of this institutionalization process suggests that organizational innovation shares the "leadership by doing" flavour of the other two engineering leadership orientations. Thus, engineers' leadership credibility depends on their realization of innovative ideas beyond the visionary or ideational stage.

A particularly interesting aspect of our three emergent engineering leadership orientations is their potential to rehabilitate Weber's (1947) "bureaucratic" authority. Weber identified three ideal types of authority-traditional, charismatic and bureaucratic - the first based on social or familial status, the second based on the personality of an individual leader and the third based on one's professional training or organizational position. Unfortunately, our negative experiences with modern bureaucracies in combination with our North American cult of the individual have caused us to dismiss the most accessible of Weber's three types. Bureaucratic authority and its associated leadership style, "transactional leadership" (Bass, 1985; Burns, 1978), have been framed as the undesirable foil to charismatic authority and its associated leadership style, "transformational leadership" (Bass, 1985; Burns, 1978). The unintended consequence of this comparison is that "effective" leadership is reduced to a single, and largely unattainable, "transformational" approach. Engineers' leadership capacity more often stems from their subject matter expertise, organizational location and coordinating responsibilities than from their social status or charismatic personalities. This suggests that if bureaucratic authority is relegated to the background of leadership theory, engineers' professional leadership potential will be similarly masked. To characterize transactional leadership as an instrumental game of rewards and punishments is to ignore the fact that leaders can blend transformational and transactional elements in their work (Yukl, 1999). Our preliminary engineering leadership theory suggests that it is possible to merge inspiration, engagement, learning and specialized training with formal organizational position and technical expertise to produce high quality, dynamic results that feel meaningful to engineers.

While our research exclusively focussed on engineers, it is important to note that research in other professions has revealed occupationally specific adjustments to leadership theory as well. Studies of leadership from the perspective of lawyers (Forrow, 1989; Rhode, 2010), doctors (Apker \& Eggly, 2004; Collins-Nakai, 2006; Goodall, 2011), professors (Goodall, 2009), scientists (Andrews \& Farris, 1967; Mumford, Scott, Gaddis, \& Strange, 2002; Robledo et al., 2012), teachers (Bascia, 1996, 1997; Casey, 1993; Henry, 1992; Lieberman, Saxl, \& Miles, 1988; Little, 1988; Rottmann, 2006; Smylie \& Denny, 1990; Wasley, 1991), and elite athletes (Bridgewater, Kahn, \& Goodall, 2011) suggest that members of many 
occupationally-defined groups reframe leadership in ways that accommodate key features of their respective professions. Thus, while the three leadership orientations listed at the bottom of our model are specific to engineering, it is possible that the concept of a compound professional leadership identity is more broadly generalizable to other occupational groups.

\section{Conclusions}

Our grounded theory of engineering leadership suggests that despite overt resistance to the word "leadership," engineers across organizational sites and industries do in fact lead. If leadership is primarily about influence, engineers in our sample led by passing on experientially gained technical insights, building bridges across organizational units and operationalizing their innovative ideas. These three modes of influence led us to identify three corresponding engineering leadership orientations - technical mastery, collaborative optimization and organizational innovation. Like Weber's (1947) three "ideal types" of authority, these three "ideal types" of engineering influence represent distinct conceptions of leadership that emerged from empirical data. They are not characterizations of great leaders; nor do they represent a set of goals to which all engineers must aspire. Rather, they denote concepts that reflect engineers' professional experiences with interpersonal, team and organisational influence. Engineers who embody one or more of these leadership orientations demonstrate ways to blend the technical, creative and humanistic elements of their profession, but their accomplishments are often invisible to themselves, to their peers and to the public at large. To the extent that we explicitly acknowledge these practices as leadership, we build engineers' capacity to serve society and facilitate public recognition for their service.

\section{Significance}

Our conceptual bridge building project has concrete implications for engineers and their organizations. At the individual level, our model has the potential to facilitate engineers' progress along a professionally meaningful career trajectory by connecting three key engineering skill sets with three corresponding modes of influence. Junior engineers who identify with the first element of each compound leadership identity have a highly valued leadership path laid out for them. At the organizational level, human resource professionals can generate meaningful professional development opportunities by blending the technical requirements of each job with professionally recognized forms of influence. They can also use the three engineering leadership orientations to build a needs-assessment for recruitment purposes.

Our emergent theory of engineering leadership also has important implications for undergraduate education. If it is true that traditional notions of leadership combined with key engineering identity features evoke resistance to the idea and practice of leadership among engineers, it behoves us as engineering educators to dedicate some curricular space to helping students unpack these assumptions. Our lessons are most likely to be deemed legitimate by students, colleagues and prospective employers if we infuse them with professionally recognized modes of 
influence and key facets of engineering identity. The three engineering leadership orientations that emerged from our grounded theoretical analysis include both criteria and thus make useful exemplars. The dispositional rather than positional nature of these orientations has the added benefit of making leadership more accessible to engineers across the career trajectory.

Our analysis of focus group and interview data suggests that engineers lead in ways that are related to, but distinct from, the leadership practices of other occupational groups. If our findings hold true across the profession, they will help us explain engineers' collective resistance to contemporary notions of leadership while diversifying and occupationally contextualizing the notion of "effective" leadership. Leadership scholars interested in applying their theories to engineering practice, representatives of professional engineering associations interested in setting standards that feel meaningful to their membership and educational policy makers who hope to develop the leadership potential of engineers in the face of overwhelming resistance to the word "leadership" would benefit from integrating key aspects of engineering identity and professionally meaningful modes of influence into their respective domains.

Finally, and perhaps most significantly, our compound theory of engineering leadership interrupts the dichotomization of technical and social skills development. It is by merging the key facets of engineering identity with professionally recognized forms of influence that engineers come to accept themselves as leaders. At the societal level, the demystification or unveiling of a compound engineering leadership identity may contribute to public recognition that engineers possess the technical skills, vision, insight and leadership capacity to improve crumbling infrastructure, build global communication networks and generate environmentally sustainable energy systems at the local, state, federal and global levels.

\section{Limitations \& Next steps}

Our theory of engineering leadership adds a level of conceptual clarity and occupational specificity to an amorphously defined term, but it is based on the experiences of only 61 engineers from four engineering-intensive firms located in a single geographic region. Our methodological choices have allowed us to generate a deeply contextualized model, but they preclude generalization to a larger population of engineers. Problems with generalizability aside, our model's greatest limitation is its heavy reliance on professional identity. If we filter leadership theory through a pre-existing identity lens, it may be more accessible and legitimate to engineers, industry leaders and engineering educators who are currently working in the profession, but it may also reify discriminatory elements within engineering socialization (Begay-Campbell, 2010; Dryburgh, 1999; Faulkner, 2007; Korte, 2009; Layne, 2007; Loui, 2005; Olesen, 2001; Tonso, 1997, 2006, 2009; Weiss, 2013). Additional research on engineering leadership is required to test the significance of this model with a representative sample of engineers, and to expand the theory of 
engineering leadership from a practical description of what is to an aspirational projection of what might be ${ }^{2}$.

\section{References}

ABET. (2011). Criteria for accrediting engineering programs: Effective for reviews during the 2012-2013 accreditation cycle. In EAC (Ed.), (pp. 24). Baltimore, MD: Engineering Accreditation Commission.

Adizes, Ichak. (1976). Mismanagement styles. California Management Review, 19(2), 5-20.

Alajek, Sal, Ham, Alan, Murdock, Heather, \& Verrett, Jonathan. (2013). Blurring the line bewteen for-credit curricular and not-for-credit extracurricular engineering learning environments. Paper presented at the Canadian Engineering Education Association Conference, Montreal, QC.

Andrews, Frank M, \& Farris, George F. (1967). Supervisory practices and innovation in scientific teams. Personnel Psychology, 67(4), 497-515.

Apker, Julie, \& Eggly, Susan. (2004). Communicating professional identity in medical socialization: Considering the ideological discourse of morning report. Qualitative Health Research, 14(3), 411-429. doi:

$10.1177 / 1049732303260577$

Argyris, Chris, \& Schon, Donald A. (1974). Theory in practice: Increasing professional effectiveness. Oxford: Jossey-Bass.

Athreya, Krishna S, Bhandari, Nidhi, Kalkhoff, Michael T, Rover, Diane T, Black, Alexandra M, Miskioglu, Elif Eda, \& Mickelson, Steven K. (2010). Work in progress-Engineering Leadership Program: A thematic learning community. Paper presented at the ASEE/IEEE Frontiers in Education Conference, Washington, DC.

Baranowski, Mitch. (2011). Rebranding engineering: Challenges and opportunities. The Bridge, 41(2), 12-16.

Bascia, Nina. (1996). Teacher leadership: Contending with adversity. Canadian Journal of Education, 21(2), 155-169.

Bascia, Nina. (1997). Invisible leadership: Teachers' union activity in schools. Alberta Journal of Educational Research, 43(2/3), 69-85.

Bass, Bernard M. (1985). Leadership and performance beyond expectation. New York: Free Press.

Bayless, David J. (2013). Developing leadership skills in engineering students: Foundational approach through enhancement of self-awarness and interpersonal communication. Paper presented at the Canadian Engineering Education Association Conference, Montreal, QC.

Begay-Campbell, Sandra. (2010). Walking in beauty on an ever-changing path: A leadership perspective from a Native American woman engineer. Leadership and Management in Engineering, 10(4), 150-152.

\footnotetext{
${ }^{2}$ Interviews with members of Engineers Without Borders and other social-change oriented groups would provide an invaluable source of data for this project..
} 
Berger, Peter. L, \& Luckmann, Thomas. (1966). The social construction of reality: A treatise in the sociology of knowledge. Garden City, NY: Anchor Books.

Bonasso, Samuel G. (2001). Engineering, leadership, and integral philosophy. Journal of Professional Issues in Engineering Education and Practice, 127(1), 17-25.

Breaux, Paul J. (2006). An effective leadership approach for today's engineer. Paper presented at the IEEE/UT International Engineering Management Conference, Austin, TX.

Bridgewater, Sue, Kahn, Lawrence M, \& Goodall, Amanda H. (2011). Substitution and complementarity between managers and subordinates: Evidence from British football. Labour Economics, 18(3), 275-286. doi: 10.1016/j.labeco.2010.10.001

Burns, James MacGregor. (1978). Leadership. New York: Harper \& Row.

Cain, Karen, \& Cocco, Sandra. (2013). Leadership development through project based learning. Paper presented at the Canadian Engineering Education Association, Montreal, QC.

Casey, Kathleen. (1993). I answer with my life: Life histories of women teachers working for social change. New York: Routledge.

Cassin, Richard B. (2003). Leadership and communication in civil engineering: Past, present, and future. Leadership and Management in Engineering, 3(3), 145147. doi: 10.1061/(ASCE)1532-6748(2003)3:3(145)

CEAB. (2008). Accreditation Criteria and Procedures 2008 (pp. 24). Ottawa, ON: Engineers Canada.

CEAB. (2012). Canadian Engineering Accreditation Board Accreditation Criteria and Procedures (pp. 114). Ottawa: Engineers Canada.

Colcleugh, David, \& Reeve, Douglas W. (2013). Translating a corporate leadership philosophy and practice to the engineering classroom. Paper presented at the Canadian Engineering Education Association Conference, Montreal, QC.

Collins-Nakai, Ruth. (2006). Leadership in medicine. McGill Journal of Medicine, 9(1), 68-73.

Corbin, Juliet, \& Strauss, Anselm. (1990). Grounded theory research: Procedures, canons, and evaluative criteria. Qualitative Sociology, 13(1), 3-21.

Croft, Elizabeth A, Winkelman, Paul, Boisvert, Alaya, \& Patten, Kristin. (2013). Global engineering leadership: Design and implementation of local and international service learning curriculum for senior engineering students. Paper presented at the Canadian Engineering Education Association Conference, Montreal, QC.

Dryburgh, Heather. (1999). Work hard, play hard: Women and professionalization in engineering--Adapting to the culture. Gender \& Society, 13(5), 664-682. doi: $10.1177 / 089124399013005006$

EC. (2009). Leading a Canadian future: The new engineer in society (pp. 3). Ottawa, ON: Canadian Engineering Leadership Forum, Engineers Canada.

EC. (2012a). Canadian engineers for tomorrow: Trends in engineering enrolment and degrees awarded 2007-2011 (pp. 63). Ottawa, ON: Engineers Canada.

EC. (2012b). Core Engineering Competencies (pp. 8). Ottawa, ON: Engineers Canada. Ellis, Leighton A, \& Petersen, Andrew K. (2011). A way forward: Assessing the demonstrated leadership of graduate civil engineering and construction 
management students. Leadership and Management in Engineering, 11(2), 88-96.

Farr, John V, \& Brazil, Donna M. (2009). Leadership skills development for engineers. Engineering Management Journal, 21(1), 3-8.

Farr, John V, Walesh, Stuart G, \& Forsythe, George B. (1997). Leadership development for engineering managers. Journal of Management in Engineering, 13(4), 38-41.

Faulkner, Wendy. (2007). "Nuts and bolts and people": Gender-troubled engineering identities. Social Studies of Science, 37(3), 331-356. doi: $10.1177 / 0306312706072175$

Flowers, Robert B. (2002). Leadership as a responsibility. Leadership and Management in Engineering, 2(3), 15-19. doi: 10.1061/(ASCE)15326748(2002)2:3(15)

Forrow, Brian D. (1989). Lawyers and leadership. The Business Lawyer, 44(4), 16991705.

Foster, Jason A, \& Sheridan, Patricia K. (2013). Exploring design identity through a "reverse engineer and improve" values elicitation activity. Paper presented at the Canadian Engineering Education Association Conference, Montreal, QC.

Froyd, Jeffrey. (2005). The Engineering Education Coalitions program. In NAE (Ed.), Educating the engineer of 2020: Adapting engineering education to the new century (pp. 82-97). Washington, DC: National Academies Press.

Glaser, Barney. (1965). The constant comparative method of qualitative analysis. Social Problems, 12(4), 436-445.

Glaser, Barney. (1978). Theoretical sensitivity. Mill Valley, CA: Sociology Press.

Glaser, Barney. (2004). Remodeling grounded theory. The Grounded Theory Review, 4(1), 1-23.

Glaser, Barney. (2013). Staying open: The use of theoretical codes in grounded theory. The Grounded Theory Review, 12(1), 3-8.

Glaser, Barney, \& Strauss, Anselm. (1967). The Discovery of Grounded Theory. Chicago: Aldine.

Goleman, Daniel. (2000). Leadership that gets results. Harvard Business Review, 72(2), 78-90.

Goodall, Amanda H. (2009). Highly cited leaders and the performance of research universities. Research Policy, 38(7), 1079-1092. doi: 10.1016/j.respol.2009.04.002

Goodall, Amanda H. (2011). Physician-leaders and hospital performance: Is there an association? Social Science \& Medicine, 73(4), 535-539. doi: 10.1016/j.socscimed.2011.06.025

Gopakumar, Govind, Dysart-Gale, Deborah, \& Akgunduz, Ali. (2013). Creating faculty buy-in: Leadership challenges in implementing CEAB graduate attributes.

Paper presented at the Canadian Engineering Education Association Conference, Montreal, QC.

Graham, Ruth. (2012a). Achieving excellence in engineering education: The ingredients of successful change (pp. 74). London: The Royal Academy of Engineering \& Massachusetts Institute of Technology. 
Graham, Ruth. (2012b). The one less traveled by: The road to lasting systemic change in engineering education. Journal of Engineering Education, 101(4), 596-600.

Graham, Ruth, Crawley, Edward, \& Mendelsohn, Bruce R. (2009). Engineering leadership education: A snapshot review of international good practice (pp. 41): Bernard M Gordon MIT Engineering Leadership Program.

Grasso, Domenico, \& Martinelli, David. (2007). Holistic engineering. The Chronicle of Higher Education, 53(28), B8-B9.

Greenleaf, Robert K. (1977). Servant leadership: A journey into the nature of legitimate power and greatness. New York: Paulist Press.

Gronn, Peter. (2002). Distributed leadership. In K. Leithwood \& P. Hallinger (Eds.), Second international handbook of educational leadership and administration (pp. 653-696). Dordrecht: Kluwer Academic Publishers.

Gronn, Peter. (2008). The future of distributed leadership. Journal of Educational Administration, 46(2), 141-158.

Ha, Minha R. (2013). Experiential learning in leadership development: Select program at McMaster University. Paper presented at the Canadian Engineering Education Association Conference, Montreal, QC.

Hanifin, Leo, E, Lee, Ross A, Weaver, Jonathan, Bloemer, Kenneth F, \& Fry, Cynthia C. (2013). The influence of culture, process, leadership and workspace on innovation and intrepreneurship in American corporations, and the implications for engineering education. Paper presented at the 120th ASEE Annual Conference and Exposition, Atlanta, GA.

Harris, Douglas E. (1989). Creativity and innovation: The elusive competitive advantage for technology-driven industries. Engineering Management International, 5(4), 233-242.

Henry, Annette. (1992). African Canadian women teachers' activism: Recreating communities of caring and resistance. The Journal of Negro Education, 61(3), 392-404.

Hernandez, Cheri Ann. (2009). Theoretical coding in grounded theory methodology. The Grounded Theory Review, 8(3), 51-66.

Hill, Stephen, Lorenz, David, Dent, Peter, \& Lutzkendorf, Thomas. (2013). Professionalism and ethics in a changing economy. Building Research \& Information, 41(1), 8-27. doi: 10.1080/09613218.2013.736201

Hsiao, Amy. (2013). Developing engineering managers: The master of engineering management program at Memorial University of Newfoundland. Paper presented at the Canadian Engineering Education Association Conference, Montreal, QC.

Ivey, Joseph M. (2002). Five critical components of leadership. Leadership and Management in Engineering, 2(2), 26-28. doi: 10.1061/(ASCE)15326748(2002)2:2(26)

Kalonji, Gretchen. (2005). Capturing the imagination: High priority reforms for engineering educators. In NAE (Ed.), Educating the engineer of 2020: Adapting engineering education to the new century (pp. 146-150). Washington, DC: National Academies Press. 
Katehi, Linda. (2005). The global engineer. In NAE (Ed.), Educating the engineer of 2020: Adapting engineering education to the new century (pp. 151-155). Washington, DC: National Academies Press.

Kerns, Sherra E, Miller, Richard K, \& Kerns, David V. (2005). Designing from a blank slate: The development of the initial Olin College curriculum. In NAE (Ed.), Educating the engineer of 2020: Adapting engineering education to the new century (pp. 98-113). Washington, DC: National Academies Press.

King, Judson C. (2012). Restructuring engineering education: Why, how and when? Journal of Engineering Education, 101(1), 1-5.

Kirschenman, Merlin. (2011). Leadership of multidisciplinary programs and systems. Leadership and Management in Engineering, 11(2), 137-140.

Korte, Russell F. (2009). How newcomers learn the social norms of an organization: A case study of the socialization of newly hired engineers. Human Resource Development Quarterly, 20(3), 285-306. doi: 10.1002/hrdq.20016

Kumar, Sanjeev, \& Hsiao, J Kent. (2007). Engineers learn "soft skills the hard way": Planting a seed of leadership in engineering classes. Leadership and Management in Engineering, 7(1), 18-23.

LaRossa, Ralph. (2005). Grounded theory methods and qualitative family research. Journal of Marriage and Family, 67(4), 837-857. doi: 10.1111/j.17413737.2005.00179.x

Layne, Peggy. (2007). In their own words: African-American women scientists tell their stories SWE Magazine, 53(2), 22-28.

Lieberman, Ann, Saxl, Ellen R, \& Miles, Matthew B. (1988). Teacher leadership: Ideology and practice. In A. Lieberman (Ed.), Building a professional culture in schools (pp. 148-166). New York: Teachers College Press.

Little, Judith Warren. (1988). Assessing the prospects for teacher leadership. In A. Lieberman (Ed.), Building a professional culture in schools (pp. 18-106). New York: Teachers College Press.

Locurcio, Ralph V, \& Mitvalsky, Kara. (2002). Mentoring: A magnet for young engineers. Leadership and Management in Engineering, 2(2), 31-33. doi: 10.1061/(ASCE)1532-6748(2002)2:2(31)

Loui, Michael C. (2005). Ethics and the development of professional identities of engineering students. Journal of Engineering Education, 94(4), 383-390.

Mallette, Leo. (2005). Theory Pi: Engineering leadership not your theory $x, y$, or $z$ leaders. Paper presented at the Institute of Electrical \& Electronic Engineers Aerospace Conference, Big Sky, MT.

Martines-Corcoles, Mario, Gracia, Francisco J, Tomas, Ines, Peiro, Jose M, \& Schobel, Markus. (2013). Empowering team leadership and safety performance in nuclear power plants: A multilevel approach. Safety Science, 51(1), 293-301. doi: 10.1016/j.ssci.2012.08.001

Mawson, Thomas C. (2001). A new focus: ASCE leadership development. Leadership and Management in Engineering, 1(1), 51-52. doi: 10.1061/(ASCE)15326748(2001)1:1(51)

McCuen, Richard H. (1999). A course on engineering leadership. Journal of Professional Issues in Engineering Education and Practice, 125(3), 79-82. 
McGrath, Laura. (2010). Report on focus groups on engineering and leadership (pp. 57). Toronto: ILead, University of Toronto.

Miles, Matthew B, \& Huberman, A Michael. (1994). Qualitative data analysis: An expanded sourcebook (2nd ed.). Thousand Oaks: Sage.

Mumford, Michael D, Scott, Ginamarie M, Gaddis, Blaine, \& Strange, Jill M. (2002). Leading creative people: Orchestrating expertise and relationships. The Leadership Quarterly, 13(6), 705-750. doi: 10.1016/S1048-9843(02)00158-3

NAE. (2004). The Engineer of 2020: Visions of Engineering in the New Century (pp. 118). Washington, DC: National Academies Press.

NAE. (2005). Educating the engineer of 2020: Adapting engineering education to the new century (pp. 208). Washington, DC: National Academy of Engineering.

NAE. (2012). Infusing real world experiences into engineering education (pp. 41). Washington, DC: National Academy of Engineering.

NAE. (2013). Educating engineers: Preparing 21st century leaders in the context of new modes of learning: Summary of a forum (pp. 45). Washington, DC: National Academy of Engineering.

Nanus, Burt. (1992). Visionary leadership: Creating a compelling sense of direction for your organization. San Francisco: Jossey-Bass.

Ning, Hongyu, Zhou, Mingjian, Lu, Qiang, \& Wen, Liqun. (2012). Team traditionality in the relationship between authority leadership and team organizational citizenship behavior. Paper presented at the International Conference on System Science, Engineering Design and Manufacturing Informatization, Chengdu, China.

Ogawa, Rodney T, \& Bossert, Steven T. (1995). Leadership as an organizational quality. Educational Administration Quarterly, 31(2), 224-243.

Olesen, Henning Salling. (2001). Professional identity as learning processes in life histories. Journal of Workplace Learning, 13(7/8), 290-297. doi: 10.1108/13665620110411076

Osagiede, Amadin, Farmer Cox, Monica, \& Ahn, Benjamin. (2013). Purdue University's Engineering Leadership Program: Addressing the shortfall of engineering leadership education. Paper presented at the 120th ASEE Annual Conference and Exposition, Atlanta, GA.

PE0. (2013). Fact Sheet: Professional Engineers Ontario. Retrieved February, 21, 2014, from http://www.peo.on.ca/index.php/ci_id/23997/la_id/1.htm

Pierson, George J. (2013). Leadership in the world's third oldest profession: Keynote speech to the American Society of Civil Engineers leadership breakfast. Leadership and Management in Engineering, 13(2), 83-85. doi: 10.1061/(ASCE)LM.1943-5630.0000224

Pitts, Simon, Klosterman, Steven, \& McGonagle, Steven. (2013). A successful approach to educating engineering leaders at the graduate level. Paper presented at the Canadian Engineering Education Assocaition Conference, Montreal, QC.

Polito, C, \& Martinich, L. (2008). Leadership: So easy even an engineer can do it! Paper presented at the IEEE International Engineering Management Conference, Estoril, Portugal. 
Porter, James. (1993). Exploiting the leadership asset of the engineer. Journal of Management in Engineering, 9(3), 227-233.

Reese, Carol. (2003). Employment history survey of ASCE's younger members. Leadership and Management in Engineering, 3(1), 33-53. doi:

10.1061/(ASCE)1532-6748(2003)3:1(33)

Reese, Carol. (2004). Employment history survey of ASCE's younger members--2003 follow up survey. Leadership and Management in Engineering, 4(4), 133-140. doi: 10.1061/(ASCE)1532-6748(2004)4:4(133)

Reeve, Douglas W. (2010). There is an urgent need for engineering leadership education. Engineering Leadership Review, 1(1), 1-6.

Reeve, Douglas W, Sacks, Robin, Rottmann, Cindy, Daniels, Frieda, \& Wray, Adam. (2013). Engineer leadership in organizations and the implications for curriculum development. Paper presented at the Canadian Engineering Education Association Conference, Montreal, QC.

Rhode, Deborah L. (2010). Lawyers and leadership. Berkeley Law. Retrieved from https://How do engineers lead revision2 for Leadership.docx

Robledo, Issac C, Peterson, David R, \& Mumford, Michael D. (2012). Leadership of scientists and engineers: A three-vector model. Journal of Organizational Behavior, 33(1), 140-147. doi: 10.1002/job.739

Rottmann, Cindy. (2006). Hegemony, settlement and resistance: The teacher leadership policy contest. Paper presented at the American Educational Research Association, San Francisco, CA.

Rover, Diane T. (2006). Policymaking and engineers. Journal of Engineering Education, 95(1), 93-95.

Simpson, Annie E, Evans, Greg J, \& Reeve, Douglas W. (2012). A summer leadership development program for chemical engineering students. Journal of Leadership Education, 11(1), 222-232.

Singh, Amarjit, \& Jampel, Gempo. (2011). Leadership flexibility space. Journal of Management in Engineering, 26(4), 176-188. doi: 10.1061/(ASCE)ME.19435479.0000017

Slates, Kevin. (2008). The effects of leadership in the high hazard construction sector: Injuries and fatalities an issue of leadership and not hazard. Leadership and Management in Engineering, 8(2), 72-76. doi: 10.1061/(ASCE)1532-6748(2008)8:2(72)

Smylie, Mark A, \& Denny, Jack W. (1990). Teacher leadership: Tensions and ambiguities in organizational perspective. Educational Administration Quarterly, 26(3), 235-259.

Snowball, David, \& Travers, Ian. (2012). "Go out and lead:" Process Safety Management. Process Safety Progress, 31(4), 343-345. doi: $10.1002 /$ prs.11523

Spillane, James P. (2006). Distributed Leadership. San Francisco: Jossey-Bass. Strong, David, \& Frank, Brian. (2013). Engineering education research and development at Queens University. Paper presented at the Canadian Engineering Education Association Conference, Montreal, QC. 
Sweeney, Kevin. (2005). International recognition of engineering degrees, programs, and accreditation systems. In NAE (Ed.), Educating the engineer of 2020: Adapting engineering education to the new century (pp. 135-144). Washington, DC: National Academies Press.

Tonso, Karen L. (1997). Advancing women in leadership: Violence(s) and silence(s) in engineering classrooms. Advancing Women, 1(1), 1-16.

Tonso, Karen L. (2006). Student engineers and engineer identity: Campus engineer identities as figured world. Cultural Studies of Science Education, 1(2), 273307. doi: $10.1007 / \mathrm{s} 11422-005-9009-2$

Tonso, Karen L. (2009). Violent masculinities as tropes for school shooters: The Montreal Massacre, the Columbine Attack, and Rethinking Schools. American Behavioral Scientist, 52(9), 1266-1285. doi: 10.1177/0002764209332545

Vallero, Daniel A. (2008). Macroethics and engineering leadership. Leadership and Management in Engineering, 8(4), 287-296.

Vest, Charles M. (2005). Educating engineers for 2020 and beyond. In NAE (Ed.), Educating the engineer of 2020: Adapting engineering education to the new century (pp. 160-170). Washington, DC: National Academies Press.

Wakeman, Thomas H. (1997). Engineering leadership in public policy resolution. Journal of Management in Engineering, 13(4), 57-60.

Wasley, Patricia A. (1991). Teachers who lead: The rhetoric of reform and the realities of practice. New York: Teachers College Press.

Weber, Max. (1947). The theory of social and economic organizations (T. Parsons, Trans.). New York: The Free Press.

Weiss, Peter E. (2013). Engineering leadership in positive space. Paper presented at the Canadian Engineering Education Association Conference, Montreal, QC.

Yukl, Gary. (1999). An evaluation of conceptual weaknesses in transformational and charismatic leadership theories. The Leadership Quarterly, 10(2), 285-305.

Zhou, Mingjian, \& Liu, Xiaohui. (2011). The understanding of the relationship between autonomy orientation and creativity: The moderating effect of authoritarian leadership. Paper presented at the International Conference on Information Management, Innovation Management and Industrial Engineering, Sanya, China. 